\title{
Signature whistles in free-ranging populations of Indo-Pacific bottlenose dolphins, Tursiops aduncus
}

Tess Gridley, ${ }^{1}$ Sea Mammal Research Unit, School of Biology, University of St Andrews, St Andrews, Fife KY16 8LB, United Kingdom and Mammal Research Institute, Department of Zoology and Entomology, University of Pretoria, Pretoria 0002, South Africa; VICTOR G. Cock Croft, Centre for Dolphin Studies, Department of Zoology, Nelson Mandela Metropolitan University, Port Elizabeth, Eastern Cape 6031, South Africa; ElIzABETH R. Hawkins, School of Environmental Science \& Management, School of Tourism \& Hospitality Management, Southern Cross University, PO Box 157, Lismore, New South Wales 2480, Australia; Michelle Lemon Blewitt, Cardno Ecology Lab, PO Box 19, St Leonards, New South Wales 1590, Australia; TADAmichi MorisaKa, Wildlife Research Center of Kyoto University, Tanaka-Sekiden-cho, Sakyo-ku, Kyoto 606-8203, Japan; VInCENT M. JANIK, Sea Mammal Research Unit, School of Biology, University of St Andrews, St Andrews, Fife KY16 8LB, United Kingdom.

\section{ABSTRACT}

Common bottlenose dolphins (Tursiops truncatus) use individually distinctive signature whistles which are highly stereotyped and function as contact calls. Here we investigate whether Indo-Pacific bottlenose dolphins (T. aduncus) use signature whistles. The frequency trace of whistle contours recorded from three genetically distinct free-ranging populations was extracted and sorted into whistle types of similar shape using automated categorization. A signature whistle identification method based on the temporal patterns in signature whistle sequences of $T$. truncatus was used to identify signature whistle types (SWTs). We then compared the degree of variability in SWTs for several whistle parameters to determine which parameters are likely to encode identity information. Additional recordings from two temporarily isolated T. aduncus made during natural entrapment events in 2008 and 2009 were analyzed for the occurrence of SWTs. All populations were found to produce SWTs; 34 SWTs were identified from recordings of free-ranging $T$. aduncus and one SWT was prevalent in each recording of the two temporarily isolated individuals. Of the parameters considered, mean frequency and maximum frequency were the least variable and therefore most likely to reflect identity information encoded in frequency modulation patterns. Our results suggest that signature whistles are commonly used by $T$. aduncus.

Key words: Indo-Pacific bottlenose dolphin, Tursiops aduncus, categorization, identity, signature whistle.

Individuals of many long-lived species form stable associations, lasting years and even decades. In these instances, maintenance of associations usually generates a 
selective pressure for individual recognition (Wanker et al. 1998, Jouventin et al. 1999, Kazial et al. 2008). Many odontocetes live in a fluid fission-fusion society (Connor 2002, Markowitz et al. 2008) where individuals form temporary groups that frequently fuse into larger parties and split into smaller ones (Smolker et al. 1992, Connor et al. 2000). Nevertheless, throughout life, individual-specific social relationships are important (Tyack and Sayigh 1997) and stable associations form (Connor et al. 2000, Wells 2003, Möller et al. 2006).

Maintenance of relationships within a constantly changing social environment is likely to require a system of individual recognition (Sayigh et al. 1999). Options for transmitting identity information underwater are limited due to restricted visibility and a reduced sense of olfaction (Kishida et al. 2007). However, acoustic signals travel particularly well through water and most cetaceans are reliant on sound generation for orientation, foraging, and social interactions (Janik 2009). Thus it is the most likely channel in which to encode and transmit identity information.

Individual distinctiveness is enhanced when differences between individuals are large and variation within individuals is minimal (Boughman and Moss 2003). Common bottlenose dolphins (Tursiops truncatus) use vocal production learning (reviewed in Janik and Slater 1997) during the development of their recognition call-the signature whistle, generating large degrees of interindividual distinctiveness (Janik 2009). Vocal learning refers to instances where the vocalizations themselves are modified as a result of experience with those of other individuals (Janik and Slater 1997, Janik 2009). Individuals develop their signature whistles through experience with their acoustic environment (Miksis et al. 2002, Fripp et al. 2005), generating a unique whistle contour with high levels of individual distinctiveness which is independent of general voice features (Janik et al. 2006). Identity information is encoded in the distinct frequency contour of these learned stereotyped signature whistles (Janik et al. 2006). Each animal has only one signature whistle and its frequency modulation pattern remains stable over decades (Sayigh et al. 1990), facilitating maintenance of long term associations and group cohesion within their fluid social structure (Scott et al. 1990, Janik and Slater 1998). Signature whistles range between 1 and $27.3 \mathrm{kHz}$ in frequency and last between 0.10 and $4.11 \mathrm{~s}$ (Buckstaff 2004, Esch et al. 2009b). They can be produced as a single element, or as connected and disconnected multi-looped forms (Esch et al. 2009b) and they are often produced in bouts containing repetitions of the same whistle type (Janik et al. 2013).

In separation contexts, signature whistles are the predominant whistle type produced by T. truncatus, comprising up to $100 \%$ of the whistles produced when animals are in isolation (Caldwell et al. 1990). Individuals emit the same signature during brief capture-release contexts and when in undisturbed, freely interacting contexts, demonstrating that they are not artefacts of stressful circumstances (Cook et al. 2004). Signature whistles play a key role in communication between groups (Quick and Janik 2012) and are likely to facilitate reunions in mother-calf pairs (Smolker et al. 1993).

Signature whistles have been documented in over 143 captive T. truncatus as well as free-ranging animals (Caldwell et al. 1990; Sayigh et al. 1990, 1999, 2007; Janik and Slater 1998). However, with the exception of bottlenose dolphins (Tursiops sp.) residing in Shark Bay, Australia (Smolker et al. 1993), little attention has been paid to whether or not congeneric species use signature whistles. Furthermore, vocal production learning, the process by which signature whistles develop in T. truncatus (Sayigh et al. 1990, Miksis et al. 2002, Fripp et al. 2005), has yet to be conclusively demonstrated in other bottlenose dolphin species. Confusion surrounding the taxo- 
nomic status of Tursiops over recent decades (e.g., Ross and Cockcroft 1990, Wang et al. 1999, Natoli et al. 2004, Charlton-Robb et al. 2011), combined with the challenging task of studying vocal communication in free-ranging animals, may partly explain why this topic has received little attention.

Key similarities in the social organization, behavior, and ecology of $T$. aduncus and the coastal form of $T$. truncatus, combined with their genetic relatedness suggest that T. aduncus may also use signature whistles. Coastal populations of both species are often small (less than 300 individuals) and resident, as demonstrated by the site fidelity of identifiable individuals (Möller and Harcourt 1998, Wilson et al. 1999, Kogi et al. 2004, Stensland et al. 2006, Currey et al. 2008, but see Reisinger and Karczmarski 2010). A fission-fusion social system is common to both species, with individuals of either sex having preferential associations (Connor et al. 2000; Möller et al. 2001, 2006; Wiszniewski et al. 2009a). Both have extended periods of maternal care, including several years with elevated rates of association between mothers and calves during lactation (Connor et al. 2000, Kogi et al. 2004).

Here we study the temporal production of stereotyped whistles in wild T. aduncus and two temporarily isolated individuals to look for evidence of signature whistles in this species. Signature whistles in T. truncatus were discovered using the same methods (Caldwell and Caldwell 1965, Caldwell et al. 1990, Janik et al. 2013). Therefore, repeated stereotyped whistle production by $T$. aduncus would be strong evidence for a similar signaling system.

\section{MATERIALS AND METHODS}

\section{Study Populations}

Acoustic recordings of $T$. aduncus were collected from three wild, free-ranging populations inhabiting the coastal waters of Plettenberg Bay, South Africa $\left(34^{\circ} 1^{\prime} \mathrm{S}\right.$, $\left.23^{\circ} 25^{\prime} \mathrm{E}\right)$, Mikura Island, Japan $\left(33^{\circ} 52^{\prime} \mathrm{N}, 139^{\circ} 36^{\prime} \mathrm{E}\right)$, and Jervis Bay, southeast Australia $\left(35^{\circ} 07^{\prime} \mathrm{S}, 150^{\circ} 42^{\prime} \mathrm{E}\right)$ and from two temporarily isolated females in Prospect Lake, Ballina, eastern Australia $\left(28^{\circ} 50^{\prime} 52^{\prime \prime} \mathrm{S}, 153^{\circ} 34^{\prime} 49^{\prime \prime} \mathrm{E}\right.$ ) (details of data collection are given in Table 1). Molecular analysis has confirmed the status of each population as T. aduncus (Möller and Beheregaray 2001, Kakuda et al. 2002, Natoli et al. 2004, Wiszniewski et al. 2009b) with significant levels of genetic differentiation apparent between populations (Wiszniewski et al. 2009b, Gridley 2011). Acoustic data were collected during focal follows (Altmann 1974) of groups of dolphins, from Plettenberg Bay, Mikura Island, and Jervis Bay. Samples from Prospect Lake, Ballina, were made opportunistically in 2008 and 2009 during a rescue event where relocation of two different mother and calf groups was required after the dolphins became entrapped in the man-made lake. During both of these rescue events, the mother-calf pairs became separated. In addition to the neonate calf in 2009, a subadult female was also temporarily captured in the lake and relocated. Recordings analyzed in this paper from these rescue events only include the periods where the mothers were freely swimming in the lake while separated from the calves and the subadult in 2009. During separation, the calves and the subadult were restrained in slings held by rescuers with the dorsal surfaces held above the water. In previous studies of T. truncatus, this kind of situation elicited high rates of signature whistle production (Sayigh et al. 1990, 2007). Each adult female had ventral speckling which is common in adults of T. aduncus but not T. truncatus (Hale et al. 2000, Amir et al. 2005) and could be 


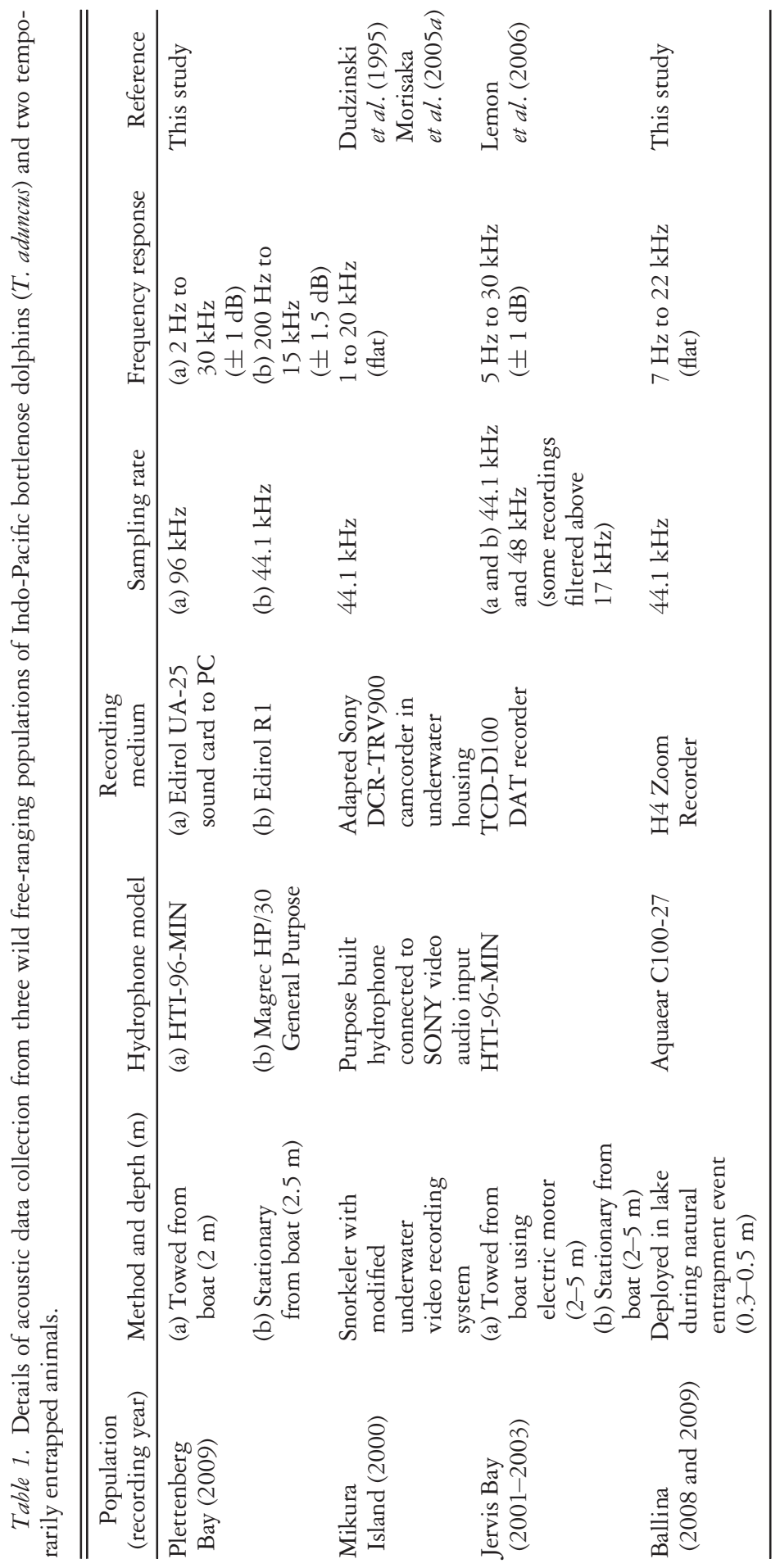


individually identified using photo-identification of dorsal fin markings (Würsig and Würsig 1977). Both were known long term (for $>5$ yr prior to entrapment) residents in a population of $T$. aduncus that used the coastal waters ( $\leq 6 \mathrm{~km}$ from the coast) and estuaries in the Ballina area (Hawkins and Gartside 2008).

\section{Acoustic Analyses}

Acoustic analyses focused on the identification of repeated stereotyped whistles as found in free-ranging (Janik et al. 2013) or isolated (Caldwell and Caldwell 1965, Sayigh et al. 2007) T. truncatus. For this, we categorized whistles into types and looked for either a bout delivery pattern as found in free-ranging T. truncatus (Janik et al. 2013) or an individually-specific whistle type used almost exclusively by isolated individuals (Caldwell and Caldwell 1965, Sayigh et al. 2007).

We use the term "contour" to describe a narrow band tonal signal with at least part of the fundamental frequency above $3 \mathrm{kHz}$. This distinguishes contours from other narrowband sounds produced by bottlenose dolphins (van der Woude 2009, Simard et al. 2012). Only contours longer than $0.1 \mathrm{~s}$ were used in this analysis (Lilly and Miller 1961, Janik et al. 2013) and harmonics other than the fundamental were not considered. A whistle is defined as a unit of one continuous contour (either single element or connected multiloop whistle) or two or more repeated contours separated by a period of silence less than $0.25 \mathrm{~s}$ in duration (disconnected multiloop whistle) (Esch et al. 2009b). Dolphins may also produce signature whistles as two or more disconnected loops without a repeated loop structure (Esch et al. 2009b). To be considered as one whistle unit these loops have to occur in the same sequence within $0.25 \mathrm{~s}$ of each other at least $80 \%$ of the time. The term "whistle type" is used to describe all whistles of a particular frequency modulation pattern as determined by automated categorization (see below). The term signature whistle type (SWT) is used to describe whistle types that showed individual distinctiveness in isolated animals (Caldwell and Caldwell 1965, Sayigh et al. 2007) or the temporal delivery pattern used by $T$. truncatus whereby signature whistles are produced in sequences separated by interwhistle intervals (IWIs) of 1-10 s (Janik et al. 2013).

Signature whistles are often produced in repetitions of the same whistle type and in a single encounter the same SWTs may be repeated many times with few other whistles recorded at the same time. To maximize the chances of sampling whistles from different free-ranging individuals we subsampled the acoustic data from Plettenberg Bay and Jervis Bay. Files were divided into short recording sections and analysis initiated from the first high quality (quality 2 or 3 , see below) contour following a random start point. Only sections containing five or more extractable contours were used and the average section length was $5 \min 34 \mathrm{~s}$ ( \pm SD 4 min $41 \mathrm{~s}$ ). This approach ensured that a similar sample size was used across populations and prevented single recordings from being over sampled thereby reducing the likelihood that the same stereotyped whistles were extracted many times. This was not necessary for Mikura as all recordings from this population were short (under $10 \mathrm{~min}$ in duration) or Ballina as we used all available recordings of isolated individuals (see below).

\section{Categorization and SIGID}

In the first step, contours were extracted as a series of frequency measurements at 5 $\mathrm{ms}$ intervals along the fundamental frequency. For this, contours from recordings of free-ranging $T$. aduncus were first visualized in the spectrogram display of Adobe 
Audition v2.0 (Hanning window, FFT size 512). Each was visually assessed and graded based on the signal-to-noise ratio (SNR) (1: signal is faint and barely visible on the spectrogram, 2: signal is clear and unambiguous, 3: signal is prominent and dominates). Extractable contours were those graded as 2 or 3 , had a clear overall shape, were unmasked and not cut off by the frequency bandwidth of the recording system. The fundamental frequency of each contour was automatically extracted in MATLAB v 6.5.1 using a supervised peak function which detects and traces the peak frequency of contours within a user defined area (display settings: FFT size 2048, 512 frame length, $87.5 \%$ overlap and a Hanning window) (Deecke and Janik 2006). The user could then edit the extracted contour to best fit the underlying contour in cases of simultaneous echolocation clicks, whistles or other sources of noise. Extracted contours were saved as a series of frequency points at $5 \mathrm{~ms}$ time resolution.

Signature whistle types were identified in each free-ranging population through contour categorization and bout analysis (SIGID, Janik et al. 2013, see below for details). Extracted contours were classified into categories using ARTwarp (Deecke and Janik 2006), an unsupervised neural network algorithm which incorporates dynamic time warping (Buck and Tyack 1993). There are two key parameters which can be adjusted to fine tune the categorization process: the warping function and the vigilance parameter (hereafter VP). Dynamic time warping allows the input contour to be "sped up" or "slowed down" in parts by a factor, termed the warping function. The VP is the level of similarity which an input contour must have with the reference contour after dynamic time warping to be classified in this category (Deecke and Janik 2006). A set of reference contours, which represent each category, are created during categorization. If the input contour does not match any of the reference contours by an amount greater than the VP then it becomes a reference contour for a new category. Following Janik et al. (2013) each recording section was categorized separately using a VP of $91 \%$ and warping function of 3 (therefore any two contours whose length differs by a factor of 3 or more are given a similarity rating of zero). The maximum number of iterations for each contour running through the ARTwarp neural network before final categorization was capped at 200, the learning rate of the neural network was 0.1 and the maximum number of categories was set to the total number of contours categorized per recording (see Deecke and Janik 2006 for further details). According to these settings, each contour could theoretically be placed into its own unique category.

Following categorization, the intercontour intervals (ICIs) of all extracted contours within the same category were calculated as the time from the contour start point to the end of the preceding contour and from the contour end point to the start of the following contour. If a contour overlapped the preceding contour in the same category, the overlapping contour was removed from consideration and the ICIs recalculated. Contours that were categorized together and separated by a period of silence up to $0.25 \mathrm{~s}$ or contours which occurred in the same sequence within $0.25 \mathrm{~s}$ of each other at least $80 \%$ of the time were classified as disconnected multilooped whistles. Repeatedly emitted whistles were those where the IWI to the preceding or following whistle was between 1 and $10 \mathrm{~s}$ of another in the same category (Janik et al. 2013), using the start time of the first loop and end time of the last loop in disconnected multilooped whistles.

Janik et al. (2013) looked at whistle types containing four or more whistles and calculated the proportion of whistles repeated within 1-10 s of each other. They found that if the proportion of whistles occurring within 1-10 s of another of the same type was $75 \%$ or higher, it was a signature whistle. They termed this approach 
to identifying signature whistles SIGID. As it is the temporal production of whistles that underlies whether a whistle is likely to be a signature whistle, this criteria can also be applied on a whistle by whistle basis (Janik et al. 2013) by searching recordings for series of whistles of the same type produced within 1-10 s (Quick and Janik 2012). We followed this approach to identify SWTs from recordings of T. aduncus by analyzing the repeated whistle types for sequences of whistles produced within 1-10 s. As we are applying this to a different species we used a more stringent criterion than suggested by Janik et al. (2013) in that we only considered whistle types containing five or more whistles from the same recording section. Therefore, for any whistle type there must be at least one point in time where whistles are produced in a sequence with a minimum of four out of five whistles produced within 1-10 s. If a whistle type fulfilled these criteria it was considered to be a SWT. Contours from categories that did not meet these criteria were classified as nonSWTs (NSWT).

Finally cross-comparison of SWTs was conducted to determine whether the same SWT was present in more than one recording section. This was necessary because two or more recording sections could be analyzed from the same encounter with the same individuals present and also because signature whistles remain stable for time periods spanning decades (Sayigh et al. 1990). The reference contours of SWTs from different recording sections were run through ARTwarp at a warping function of two, and VP of $91 \%$. A lower warping function was used here, since average contours of the same signature whistle in different encounters should not differ by much in their contour. If the reference contours grouped together, the composing whistles were grouped together and counted as one unique SWT.

\section{Variability in Signature Whistle Type Parameters from Free-ranging T. aduncus}

Certain whistle parameters may be more likely to encode identity information than others. We investigated the variation in SWT parameters for each population by calculating the coefficient of variation $[\mathrm{CV}=100 \times$ (standard deviation/mean)] for each whistle type and generating an average ( $\mathrm{CV} i$ ) of these for the following seven standard whistle parameters (following those outlined by Oswald et al. 2003, Morisaka et al. 2005b); start, end, minimum and maximum frequency, the frequency range, mean frequency (average of all the frequency points at $5 \mathrm{~ms}$ resolution making up the contour), and duration (s). The frequency and duration parameters were automatically measured from extracted whistles using purpose written MATLAB script.

\section{Recordings of Isolated T. aduncus from Ballina, eastern Australia}

All available contours from the recordings of two entrapped isolated T. aduncus were independently visually categorized by three experienced judges (the authors: TG, VMJ, and EH) for the occurrence of whistle types. Whistle contours from a subsection of each recording were extracted $(n=10)$ and automatically categorized in ARTwarp using the same settings as described above and with a warping function of three.

\section{RESULTS}

Signature whistle types were identified in all free-ranging populations as well as recordings of the two temporarily isolated individuals. 
Table 2. Summary of acoustic data used to identify signature whistle types (SWTs). Only recording sections containing five or more extracted contours were included in this analysis. To remove replicates, SWTs were finalized after cross comparison of reference contours between recording sections using ARTwarp categorization with a warping function of 2 .

\begin{tabular}{lcccccc}
\hline \hline & $\begin{array}{c}\text { Recording } \\
\text { days }\end{array}$ & $\begin{array}{c}\text { No. of } \\
\text { sections } \\
\text { analyzed }\end{array}$ & $\begin{array}{c}\text { No. of } \\
\text { contours } \\
\text { extracted }\end{array}$ & $\begin{array}{c}\text { No. of } \\
\text { ARTwarp } \\
\text { categories }\end{array}$ & $\begin{array}{c}\text { Mean }( \pm \text { SD) } \\
\text { no. of whistles } \\
\text { per SWT category }\end{array}$ & $\begin{array}{c}\text { No. SWT } \\
\text { identified }\end{array}$ \\
\hline $\begin{array}{l}\text { Plettenberg } \\
\text { Bay }\end{array}$ & 10 & 16 & 511 & 137 & $14(10.7)$ & 12 \\
$\begin{array}{l}\text { Mikura } \\
\text { Jervis Bay }\end{array}$ & 6 & 24 & 685 & 163 & $24(22.9)$ & 12 \\
\hline
\end{tabular}

${ }^{a}$ The number of recording days in Jervis Bay is a minimum as recordings from several days were occasionally stored on the same Digital Audio Tape (DAT).

\section{Signature Whistle Types in Free-ranging T. aduncus}

In total, more than $17 \mathrm{~h}$ of acoustic recordings of free-ranging $T$. aduncus were considered for analysis. After subsampling, over 3,652 contours were identified, of which $1 \%$ were cut off by the frequency bandwidth of the recording system. In total 1,634 contours were extracted from 61 recording sections ( $4 \mathrm{hr} 25 \mathrm{~min}$ ) made over $>26 \mathrm{~d}$ (Table 2). Of these, 818 contours $(50 \%)$ were identified as either a continuous SWT or a constituent loop of a disconnected SWT, 805 (49\%) were classified as NSWTs and $11(1 \%)$ overlapped another contour in the same category and were removed from analysis. In total, 34 SWTs were identified. This included 12 from Plettenberg Bay, 12 from Mikura Island, and 10 from Jervis Bay (see Fig. 1 for examples). Of these 34 SWTs, 15 were identified in two or more recording sections.

\section{Variability in Signature Whistle Type Parameters}

The number of whistles in each SWT ranged between 5 and 77, with mean values of 14 ( \pm SD 10.7), 24 ( \pm SD 22.9), and 26 ( \pm SD 21.9) whistles per SWT for Plettenberg Bay, Mikura Island, and Jervis Bay, respectively. The variation in SWT parameters was lowest for mean frequency and maximum frequency (range $\mathrm{CV} i=$ 6.3-8.2 and 6.4-11.2, respectively) and generally high for frequency range and duration (range $\mathrm{CV} i=20.0-30.3$ and 15.9-35.8, respectively), although there was population variation in this (Fig. 2).

\section{Signature Whistle Types in Isolated T. aduncus from Ballina, eastern Australia}

The contours from $1 \mathrm{hr} 26 \mathrm{~min}$ of recording from two isolated T. aduncus were visually categorized (12 min from animal a, $1 \mathrm{hr} 14 \mathrm{~min}$ from animal b). On each occasion a single stereotyped whistle type was prevalent and produced repeatedly, comprising $100 \%(n=395)$ and $87 \%(n=368)$ of the whistles from recordings of animal a and b respectively (Fig. 3). The extracted whistle contours from each subsection were categorized together by ARTwarp with a high similarity rating (97\%99\%). Stereotyped whistles were produced in bouts containing sequences of five or more whistles produced at IWIs of 1-10 s, i.e., both whistle a and b were SWTs. The 
(a) Plettenberg Bay

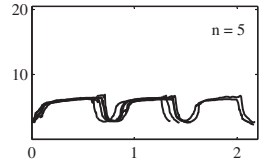

(b) Mikura Island

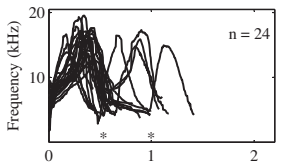

(c) Jervis Bay

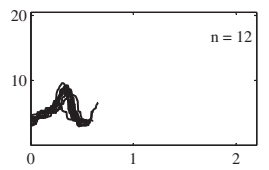

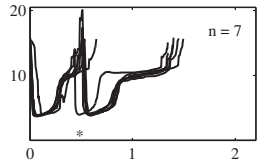
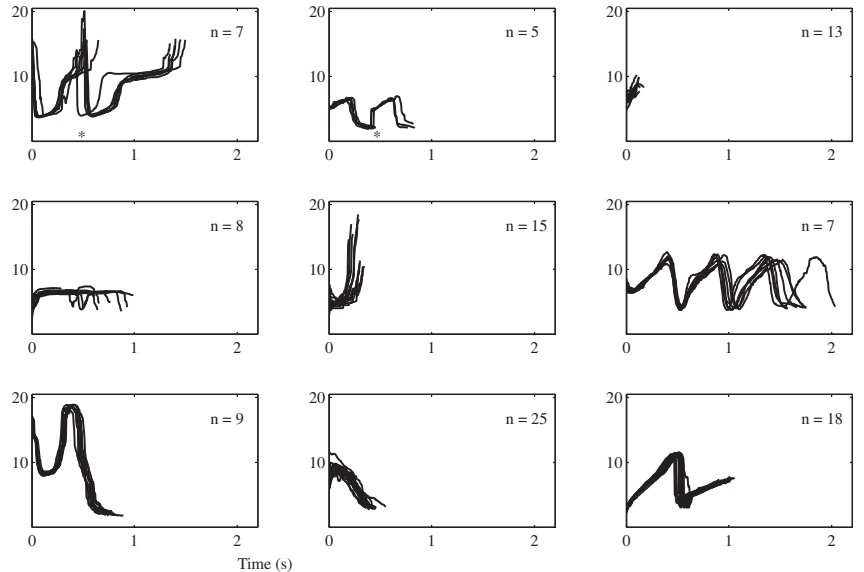

Figure 1. Representative signature whistle types (SWTs) identified from three free-ranging populations of $T$. aduncus through contour categorization in ARTwarp and bout analysis (SIGID, Janik et al. 2013). Disconnected multilooped SWTs include a period of silence $0.03-0.25 \mathrm{~s}$ long. This silent period (not plotted) occurs at the position of an inflection point, marked with an asterisk $(*)$ on three of the plots.

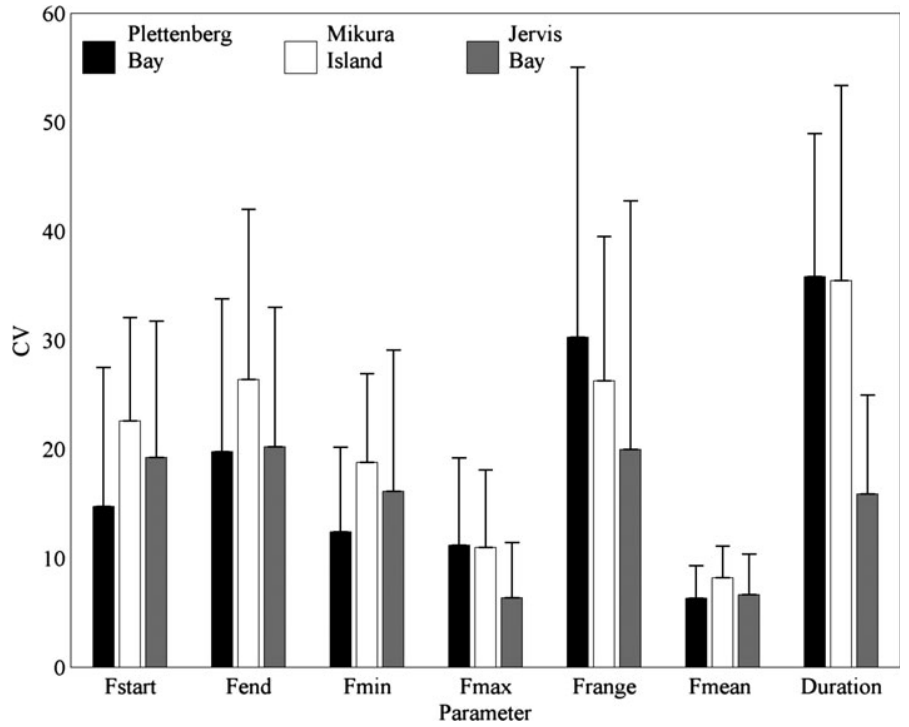

Figure 2. Mean ( \pm SD) coefficient of variation in signature whistle type parameters for three populations of $T$. aduncus. Frequency $(\mathrm{kHz})$ denoted by $\mathrm{F}$.

context at the time of recording (isolation and separation from calf), the stereotyped call nature and the temporal pattern of whistle production, which mirrors that of $T$. truncatus, shows that these are signature whistles. 


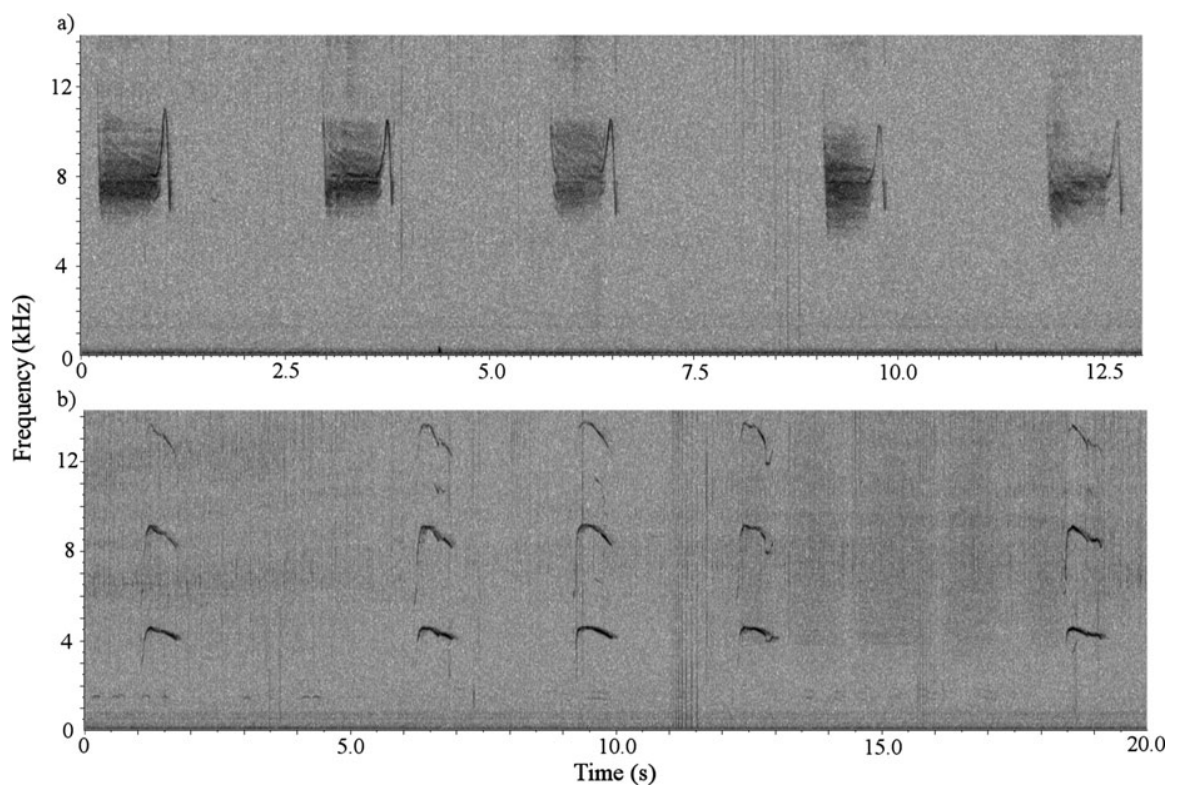

Figure 3. Spectrogram of signature whistle types from recordings of two different adult $T$. aduncus during temporary isolation and separation from their calf. Both animals were recorded in Prospect Lake, Ballina (eastern Australia) in 2008 (a) and 2009 (b). Note different scale to x axis on (a) and (b).

\section{DisCUSSION}

This study has demonstrated clear stereotyped categories in the whistle repertoires of $T$. aduncus and provides evidence that this species is using signature whistles. In total, 34 SWTs were identified in recordings from three geographically separated and genetically distinct populations of free-ranging $T$. aduncus and a further two SWTs were identified from recordings of known isolated individuals. The identification of SWTs in recordings of both freely-ranging and isolated T. aduncus from several populations provides good evidence that these call types have functional importance in the vocal repertoire of $T$. aduncus.

Previous studies have used temporary capture (Cook et al. 2004, Watwood et al. 2005), localization (Janik and Slater 1998) or tagging (Shapiro 2006) to assign signature calls to individuals. When captures are risky for animals, or when logistical and financial reasons do not allow for captures, reliable identification of signature whistles is challenging. While we cannot be certain that each SWT identified from the three free-ranging populations is produced by a different individual, the pattern and timing of contour occurrence (i.e., repeatedly emitted whistles produced at intervals of 1-10 s), mirrors that of $T$. truncatus producing individually distinctive signature whistles in freely interacting contexts (Janik et al. 2013) and thus provides evidence that each SWT was emitted by a different individual. Although dolphins can copy each other's signature whistles (Tyack 1986, Janik and Slater 1998), in the wild matching is rare and mostly involves two animals each producing just one whistle (Janik 2000). Therefore, whistle matching is unlikely to have influenced our results, particularly as we removed overlapping contours of the same type from the analysis. 
Considering what we know of signature whistle production in T. truncatus and how it varies with behavioral context (Cook et al. 2004, Esch et al. 2009a), it is not surprising that signature whistles were recorded in the presence of individuals entrapped in Prospect Lake, Ballina, when mothers were separated from their calves and the subadult. The high proportion of SWTs produced $(100 \%$ and $87 \%)$ is in accordance with the proportions of signature whistles reported by Caldwell et al. (1990) for isolated individuals. A second whistle type was apparent at the start of the recording of animal b in 2009. This may be the SWT of the subadult which was being stabilized in a sling at the start of this recording or perhaps a second whistle type produced by animal b, however, without acoustic localization it is not possible to be sure. Across the three free-ranging populations, the average number of contours categorized into SWTs by ARTwarp (50\%) was comparable to the value of $52 \%$ of whistles identified by Cook et al. (2004) when investigating rates of signature whistle production by free-ranging T. truncatus. The predominance of SWTs in both isolated and free-ranging contexts demonstrates the importance of this category in the vocal repertoire of $T$. aduncus.

Frequency range and duration had comparatively high degrees of variation within SWTs (Fig. 2). Signals used to express motivational state are likely to be highly variable (Falls 1982) and previous research has demonstrated that the number and duration of loops are affected by behavioral context (Esch et al. 2009a). Maturation may also play a role, with older animals producing longer whistles (Caldwell et al. 1990). Therefore it seems that whistle duration, which is often though not exclusively, a function of the number of repeated loops in a SWT (Caldwell et al. 1990, Gridley 2011), is a poor encoder of identity information in T. aduncus. Mean frequency was the least variable SWT parameter for all populations. This is not surprising considering that the main carrier of identity information in T. truncatus is the overall frequency modulation pattern of the whistle (Janik et al. 2006) and as SWTs are stereotyped this would be well reflected by the mean frequency parameter.

In general, whistles of $T$. aduncus are shorter than T. truncatus (Gridley et al. 2012) and it is therefore possible that the signature whistles of $T$. aduncus are also shorter in duration. Of the SWTs identified from the free-ranging populations, five were relatively short in duration (around $0.25 \mathrm{~s}$ or less). These short whistles were mostly upsweeps and unlike the majority of SWT identified had similar frequency modulation patterns and frequency characteristics across populations. These short SWTs may be too simplistic in nature to accurately convey identity information and they may instead be chirps (short whistles less than $0.25 \mathrm{~s}$ in duration, Richards et al. 1984) which can also be produced in repeated emissions (Janik et al. 2013). However, further investigation is necessary to determine the function of these short whistle types.

Additional research is required to understand the function of SWTs in T. aduncus and establish whether they fulfill the same role as signature whistles in T. truncatus. Tagging studies (Johnson and Tyack 2003) or temporary captures (Sayigh et al. 1999, Janik et al. 2006) would help to confirm individual variation in whistles. Detailed captive studies, particularly those in controlled conditions involving newborn calves would help to understand signature whistle ontogeny (Caldwell and Caldwell 1979), signature whistle stability through time, and would be useful in determining whether $T$. aduncus are capable of vocal production learning.

Categorization in ARTwarp offers a fast and consistent way to divide repertoires and can be widely applied to help understand whistle communication in a range of species. Observations of stereotyped whistles in several delphinid species (Caldwell and Caldwell 1968, Caldwell et al. 1973, Van Parijs and Corkeron 2001, de 
Figueiredo and Simao 2009) pose a case for a broader use of signature whistles which could be investigated using automated categorization in ARTwarp and the SIGID method.

\section{ACKNOWLEDGMENTS}

This research was supported by a NERC studentship and a University of St Andrews Russell Trust Award to TG, a Royal Society University Research Fellowship and a Fellowship of the Wissenschaftskolleg zu Berlin to VMJ. Funding for MLB was through an Australian Postgraduate Award, Graduate School of the Environment, Macquarie University, NSW, the Jervis Bay Marine Parks Authority and Dolphin Watch Cruises, Jervis Bay. The authors would like to thank everyone involved in the fieldwork for their help to collect this data. In particular, volunteers from the Centre for Dolphin Studies (SA), Steve Bebington, MikuraJima Iruka Kyoukai, Kazunobu Kogi, and Masanori Shinohara. We also thank Volker Deecke for providing ARTwarp advice and Simon Elwen for useful comments on an earlier draft of this manuscript.

\section{Literature Cited}

Altmann, J. 1974. Observational study of behaviour: Sampling methods. Behaviour 49:227267.

Amir, O. A., N. S. Jiddawi and P. Berggren. 2005. The occurence and distribution of dolphins in Zanzibar, Tanzania, with comments on differences between two species of Tursiops. Western Indian Ocean Journal of Marine Science 4:85-93.

Boughman, J. W., and C. F. Moss. 2003. Social sounds: Vocal learning and development of mammal and bird calls. Pages 138-224 in A. M. Simmons, A. N. Popper and R. R. Fay, eds. Acoustic communication. Springer-Verlag, New York, NY.

Buck, J. R., and P. L. Tyack. 1993. A quantitative measure of similarity for Tursiops truncatus signature whistles. Journal of the Acoustical Society of America 94:2497-2506.

Buckstaff, K. C. 2004. Effects of watercraft noise on the acoustic behavior of bottlenose dolphins, Tursiops truncatus, in Sarasota Bay, Florida. Marine Mammal Science 20:709725 .

Caldwell, M. C., and D. K. Caldwell. 1965. Individualized whistle contours in bottlenosed dolphins (Tursiops truncatus). Nature 207:434-435.

Caldwell, M. C., and D. K. Caldwell. 1968. Vocalization of native captive dolphins in small groups. Science 159:1121-1123.

Caldwell, M. C., and D. K. Caldwell. 1979. The whistle of the Atlantic bottlenosed dolphin (Tursiops truncatus) —ontogeny. Pages 369-401 in H. E. Winn, ed. Behaviour of marine animals. Plenum Press, New York. NY.

Caldwell, M. C., D. K. Caldwell and J. F. Miller. 1973. Statistical evidence for individual signature whistles in the spotted dolphin, Stenella plagiodon. Cetology 16:1-21.

Caldwell, M. C., D. K. Caldwell and P. L. Tyack. 1990. Review of the signature-whistle hypothesis for the Atlantic bottlenose dolphin. Pages 199-234 in S. Leatherwood and R. R. Reeves, eds. The bottlenose dolphin. Academic Press, San Diego, CA.

Charlton-Robb, K., L.-A. Gershwin, R. Thompson, J. Austin, K. Owen and S. Mckechnie. 2011. A new dolphin species, the burrunan dolphin Tursiops australis sp. nov., endemic to southern Australian coastal waters. Plos One 6:E24047.

Connor, R. C. 2002. Ecology of group living and social behaviour. Pages 353-370 in A. R. Hoelzel, ed. Marine mammal biology: An evolutionary approach. Blackwell, Oxford, U.K.

Connor, R. C., R. S. Wells, J. Mann and A. . 2000. The bottlenose dolphin: Social relationships in a fission-fusion society. Pages 91-126 in J. Mann, R. C. Connor, P. L. 
Tyack and H. Whitehead, eds. Cetacean societies: Field studies of dolphins and whales. The University of Chicago Press, Chicago, IL.

Cook, M. L. H., L. S. Sayigh, J. E. Blum and R. S. Wells. 2004. Signature-whistle production in undisturbed free-ranging bottlenose dolphins (Tursiops truncatus). Proceedings of the Royal Society of London Series B-Biological Sciences 271:1043-1049.

Currey, R. J. C., L. E. Rowe, S. M. Dawson and E. Slooten. 2008. Abundance and demography of bottlenose dolphins in Dusky Sound, New Zealand, inferred from dorsal fin photographs. New Zealand Journal of Marine and Freshwater Research 42:439-449.

de Figueiredo, L. D. and S. M. Simão. 2009. Possible occurrence of signature whistles in a population of Sotalia guianensis (Cetacea, Delphinidae) living in Sepetiba Bay, Brazil. Journal of the Acoustical Society of America 126:1563-1569.

Deecke, V. B., and V. M. Janik. 2006. Automated categorization of bioacoustic signals: Avoiding perceptual pitfalls. Journal of the Acoustical Society of America 119:645-653.

Dudzinski, K. M., C. W. Clark and B. Würsig. 1995. A mobile video/acoustic system for simultaneous underwater recording of dolphin interactions. Aquatic Mammals 21:187193.

Esch, H. C., L. S. Sayigh, J. E. Blum and R. S. Wells. 2009a. Whistles as potential indicators of stress in bottlenose dolphins (Tursiops truncatus). Journal of Mammalogy 90:638-650.

Esch, H. C., L. S. Sayigh and R. S. Wells. 2009b. Quantifying parameters of bottlenose dolphin signature whistles. Marine Mammal Science 25:976-986.

Falls, J. B. 1982. Individual recognition by sounds in birds. Pages 237-278 in D. E. Kroodsma and E. H. Miller, eds. Acoustic communication in birds. Academic Press, New York, NY.

Fripp, D., C. Owen, E. Quintana-Rizzo, A. Shapiro, et al. 2005. Bottlenose dolphin (Tursiops truncatus) calves appear to model their signature whistles on the signature whistles of community members. Animal Cognition 8:17-26.

Gridley, T. 2011. Geographic and species variation in bottlenose dolphin (Tursiops spp.) signature whistle types. Ph.D. thesis, University of St Andrews, St Andrews, U.K. 224 pp.

Gridley, T., P. Berggren, V. G. Cockcroft and V. M. Janik. 2012. Whistle vocalizations of Indo-Pacific bottlenose dolphins (Tursiops aduncus) inhabiting the south-west Indian Ocean. Journal of the Acoustical Society of America 132:4032-4040.

Hale, P. T., A. S. Barreto and G. J. B. Ross. 2000. Comparative morphology and distribution of the aduncus and truncatus forms of bottlenose dolphin Tursiops in the Indian and Western Pacific Oceans. Aquatic Mammals 26:101-110.

Hawkins, E. R., and D. F. Gartside. 2008. Social and behavioural characteristics of IndoPacific bottlenose dolphins (Tursiops aduncus) in northern New South Wales, Australia. Australian Mammalogy 30:71-82.

Janik, V. M. 2000. Whistle matching in wild bottlenose dolphins (Tursiops truncatus). Science 289:1355-1357.

Janik, V. M. 2009. Acoustic communication in delphinids. Advances in the Study of Behavior 40:123-157.

Janik, V. M., and P. J. B. Slater. 1997. Vocal learning in mammals. Advances in the Study of Behavior 26:59-99.

Janik, V. M., and P. J. B. Slater. 1998. Context-specific use suggests that bottlenose dolphin signature whistles are cohesion calls. Animal Behaviour 56:829-838.

Janik, V. M., L. S. Sayigh and R. S. Wells. 2006. Signature whistle shape conveys identity information to bottlenose dolphins. Proceedings of the National Academy of Sciences of the United States of America 103:8293-8297.

Janik, V. M., S. L. King, L. S. Sayigh and R. S. Wells. 2013. Identifying signature whistles from recordings of groups of unrestrained bottlenose dolphins (Tursiops truncatus). Marine Mammal Science 29:109-122.

Johnson, M. P., and P. L. Tyack. 2003. A digital acoustic recording tag for measuring the response of wild marine mammals to sound. IEEE Journal of Oceanic Engineering 28:312. 
Jouventin, P., T. Aubin and T. Lengagne. 1999. Finding a parent in a king penguin colony: The acoustic system of individual recognition. Animal Behaviour 57:11751183.

Kakuda, T., Y. Tajima, K. Arai, K. Kogi, T. Hishii and T. K. Yamada. 2002. On the resident "bottlenose dolphins" from Mikura water. Memoirs of the National Science Museum, Tokyo 38:255-272.

Kazial, K. A., T. L. Kenny and S. C. Burnett. 2008. Little brown bats (Myotis lucifugus) recognize individual identity of conspecifics using sonar calls. Ethology 114:469-478.

Kishida, T., S. Kubota, Y. Shirayama and H. Fukami. 2007. The olfactory receptor gene repertoires in secondary-adapted marine vertebrates: Evidence for reduction of the functional proportions in cetaceans. Biology Letters 3:428-430.

Kogi, K., T. Hishii, A. Imamura, T. Iwatani and K. M. Dudzinski. 2004. Demographic parameters of Indo-Pacific bottlenose dolphins (Tursiops aduncus) around Mikura Island, Japan. Marine Mammal Science 20:510-526.

Lemon, M., T. P. Lynch, D. H. Cato and R. G. Harcourt. 2006. Response of travelling bottlenose dolphins (Tursiops aduncus) to experimental approaches by a powerboat in Jervis Bay, New South Wales, Australia. Biological Conservation 127:363-372.

Lilly, J. C., and A. M. Miller. 1961. Sounds emitted by the bottlenose dolphin. Science 133:1689-1693.

Markowitz, T. M., W. J. Markowitz and L. M. Morton. 2008. Mating habits of New Zealand dusky dolphins. Pages 151-176 in B. Würsig and M. Würsig, eds. The dusky dolphin: Master acrobat off different shores. Elsevier, London, U.K.

Miksis, J. L., P. L. Tyack and J. R. Buck. 2002. Captive dolphins, Tursiops truncatus, develop signature whistles that match acoustic features of human-made model sounds. Journal of the Acoustical Society of America 112:728-739.

Möller, L. M. and L. B. Beheregaray. 2001. Coastal bottlenose dolphins from southeastern Australia are Tursiops aduncus according to sequences of the mitochondrial DNA control region. Marine Mammal Science 17:249-263.

Möller, L. M., and R. G. Harcourt. 1998. Social dynamics and activity patterns of bottlenose dolphins, Tursiops truncatus, in Jervis Bay, southeastern Australia. Proceedings of the Linnean Society of New South Wales 120:181-189.

Möller, L. M., L. B. Beheregaray, R. G. Harcourt and M. Krutzen. 2001. Alliance membership and kinship in wild male bottlenose dolphins (Tursiops aduncus) of southeastern Australia. Proceedings of the Royal Society of London Series B-Biological Sciences 268:1941-1947.

Möller, L. M., L. B. Beheregaray, S. J. Allen and R. G. Harcourt. 2006. Association patterns and kinship in female Indo-Pacific bottlenose dolphins (Tursiops aduncus) of southeastern Australia. Behavioral Ecology and Sociobiology 61:109-117.

Morisaka, T., M. Shinohara, F. Nakahara and T. Akamatsu. 2005a. Effects of ambient noise on the whistles of Indo-Pacific bottlenose dolphin populations. Journal of Mammalogy 86:541-546.

Morisaka, T., M. Shinohara, F. Nakahara and T. Akamatsu. 2005b. Geographic variations in the whistles among three Indo-Pacific bottlenose dolphin Tursiops aduncus populations in Japan. Fisheries Science 71:568-576.

Natoli, A., V. M. Peddemors and A. R. Hoelzel. 2004. Population structure and speciation in the genus Tursiops based on microsatellite and mitochondrial DNA analyses. Journal of Evolutionary Biology 17:363-375.

Oswald, J. N., J. Barlow and T. F. Norris. 2003. Acoustic identification of nine delphinid species in the eastern tropical Pacific Ocean. Marine Mammal Science 19:20-37.

Quick, N. J., and V. M. Janik. 2012. Bottlenose dolphins exchange signature whistles when meeting at sea. Proceedings of the Royal Society B 279:2539-2545.

Reisinger, R. R., and L. Karczmarski. 2010. Population size estimate of Indo-Pacific bottlenose dolphins in the Algoa Bay region, South Africa. Marine Mammal Science 26:86-97. 
Richards, D. G., J. P. Wolz and L. M. Herman. 1984. Vocal mimicry of computer-generated sounds and vocal labeling of objects by a bottlenosed dolphin, Tursiops truncatus. Journal of Comparative Physiology 98:10-28.

Ross, G. J. B., and V. G. Cockcroft. 1990. Comments on Australian bottlenose dolphins and the taxonomic status of Tursiops aduncus (Ehrenberg, 1832). Pages 101-128 in S. Leatherwood and R. R. Reeves, eds. The bottlenose dolphin. Academic Press, San Diego, CA.

Sayigh, L. S., P. L. Tyack, R. S. Wells and M. D. Scott. 1990. Signature whistles of freeranging bottlenose-dolphins Tursiops truncatus: Stability and mother offspring comparisons. Behavioral Ecology and Sociobiology 26:247-260.

Sayigh, L. S., P. L. Tyack, R. S. Wells, A. R. Solow, M. D. Scott and A. B. Irvine. 1999. Individual recognition in wild bottlenose dolphins: A field test using playback experiments. Animal Behaviour 57:41-50.

Sayigh, L. S., H. C. Esch, R. S. Wells and V. M. Janik. 2007. Facts about signature whistles of bottlenose dolphins, Tursiops truncatus. Animal Behaviour 74:1631-1642.

Scott, M. D., R. S. Wells and A. B. Irvine. 1990. A long-term study of bottlenose dolphins on the west coast of Florida. Pages 235-244 in S. Leatherwood and R. Reeves, eds. The Bottlenose dolphin recent progress in research. Academic Press, San Diego, CA.

Shapiro, A. D. 2006. Preliminary evidence for signature vocalizations among free-ranging narwhals (Monodon monoceros). Journal of the Acoustical Society of America 120:16951705.

Simard, P., N. Lace, S. Gowans, E. Quintana-Rizzo, S. A. II Kuczaj, R. S. Wells and D. A. Mann. 2012. Low frequency narrow-band calls in bottlenose dolphins (Tursiops truncatus): Signal properties, function, and conservation implications. Journal of the Acoustical Society of America 130:3068-3076.

Smolker, R. A., A. F. Richards, R. C. Connor and J. W. Pepper. 1992. Sex-differences in patterns of association among Indian Ocean bottlenose dolphins. Behaviour 123:38-69.

Smolker, R. A., J. Mann and B. B. Smuts. 1993. Use of signature whistles during separations and reunions by wild bottlenose dolphin mothers and infants. Behavioral Ecology and Sociobiology 33:393-402.

Stensland, E., I. Carlen, A. Sarnblad, A. Bignert and P. Berggren. 2006. Population size, distribution, and behavior of Indo-Pacific bottlenose (Tursiops aduncus) and humpback (Sousa chinensis) dolphins off the south coast of Zanzibar. Marine Mammal Science 22:667-682.

Tyack, P. L. 1986. Whistle repertoires of two bottlenosed dolphins, Tursiops truncatus: Mimicry or signature whistles? Behavioral Ecology and Sociobiology 18:251-257.

Tyack, P. L., and L. S. Sayigh. 1997. Vocal learning in cetaceans. Pages 208-233 in C. T. Snowdon and M. Lausberger, eds. Social influences on vocal development. Cambridge University Press, Cambridge, U.K.

van der Woude, S. E. 2009. Bottlenose dolphins (Tursiops truncatus) moan as low in frequency as baleen whales. Journal of the Acoustical Society of America 126:1552-1562.

Van Parijs, S. M., and P. J. Corkeron. 2001. Evidence for signature whistle production by a Pacific humpback dolphin, Sousa chinensis. Marine Mammal Science 17:944-949.

Wang, J. Y., L. S. Chou and B. N. White. 1999. Mitochondrial DNA analysis of sympatric morphotypes of bottlenose dolphins (genus: Tursiops) in Chinese waters. Molecular Ecology 8:1603-1612.

Wanker, R., J. Apcin, B. Jennerjahn and B. Waibel. 1998. Discrimination of different social companions in spectacled parrotlets (Forpus conspicillatus): Evidence for individual vocal recognition. Behavioral Ecology and Sociobiology 43:197-202.

Watwood, S. L., E. C. G. Owen, P. L. Tyack and R. S. Wells. 2005. Signature whistle use by temporarily restrained and free-swimming bottlenose dolphins, Tursiops truncatus. Animal Behaviour 69:1373-1386.

Wells, R. S. 2003. Dolphin social complexity: Lessons from long-term study and life history. Pages 32-56 in F. B. M. De Waal and P. L. Tyack, eds. Animal social complexity: 
Intelligence, culture, and individualized societies. Harvard University Press, Cambridge, MA.

Wilson, B., P. S. Hammond and P. M. Thompson. 1999. Estimating size and assessing trends in a coastal bottlenose dolphin population. Ecological Applications 9:288-300.

Wiszniewski, J., S. J. Allen and L. M. Moller. 2009a. Social cohesion in a hierarchically structured embayment population of Indo-Pacific bottlenose dolphins. Animal Behaviour 77:1449-1457.

Wiszniewski, J., L. B. Beheregaray, S. J. Allen and L. M. Möller. 2009b. Environmental and social influences on the genetic structure of bottlenose dolphins (Tursiops aduncus) in Southeastern Australia. Conservation Genetics 11:1405-1419.

Würsig, B., and M. Würsig. 1977. Photographic determination of group-size, composition, and stability of coastal porpoises (Tursiops truncatus). Science 198:755-756. 